\title{
The International Society of Physiotherapy Journal Editors
}

I June 2007, 59 editors from 41 physiotherapy journals met at the quadrennial conference of the World Confederation of Physical Therapy (WCPT) in Vancouver. The purpose of the meeting was to inaugurate the International Society of Physiotherapy Journal Editors (ISPJE). In the period of just two hours, participants negotiated a constitution, and a new society was born.

The idea for the society arose from an earlier meeting of journal editors, convened at the preceding WCPT Congress in 2003, by Professor Celia Eales (Editor of the South African Journal of Physiotherapy) and Professor Jules Rothstein (Editor, Physical Therapy). Following that meeting, Professor Anne Moore (Editor of Manual Therapy) and Dr Rob Herbert (Editor of the Australian Journal of Physiotherapy) agreed to establish a society that would convene regular meetings of physical therapy journal editors.

The roles of the new ISPJE are to provide a forum to discuss issues related to the publication of physical therapy journals, enhance collaboration (sharing and learning) among physical therapy journals, facilitate improvement in quality of publications within the field of physical therapy, and promote physical therapy publications worldwide. These broad aims leave open possibilities to pursue many activities, and it will be up to the members of the new society to establish its priorities.

My personal hopes are that the society will undertake activities that will benefit the broad membership of journal editors. The society should be able to provide assistance to emerging journals, for example by providing information about best practice in scientific publication, and, perhaps, by assisting journals to establish efficient processes for management of manuscripts. In addition, the society can act as a representative of physical therapy journals and the community of physical therapy researchers in matters to do with physical therapy research and scientific publication.

The society could also benefit Physical Therapy researchers and readers of physical therapy journals. We are currently in the process of setting up an on-line database that identifies physical therapy journals and provides key information about matters such as the journals' subscriber bases, which databases each journal is indexed on, the type of papers the journals publish, submission processes, journal contact details, and so on. This should make it easier for physical therapy researchers to be able to identify the most appropriate physical therapy journals in which to publish their work.

I strongly hope that the society will facilitate sharing of physical therapy research with physiotherapists in developing countries by promoting initiatives such as the Health InterNetwork Access to Research Initiative (HINARI) project (Katikireddi ${ }^{1}$ ). A personal goal is to ensure that, in the near future, all physical therapy journals published in electronic format are made freely available to developing countries. 
One of the first tasks for the society will be to comment on the World Medical Association's Declaration of Helsinki on Ethical Principles for Medical Research Involving Human Subjects (World Medical Association Ethics Unit 2007)². The Helsinki Declaration provides guidance on ethical research practices. The ISPJE will comment on the draft revision of the Helsinki Declaration through the WCPT, which is a registered stakeholder with the World Medical Association.

The standing of journals is often measured with an index called an 'impact factor'. Impact factors measure the average number of citations to papers published in a journal; it is believed by some that this provides a measure of the importance or significance of a journal (Garfield 1955, but c.f. Seglen 1997). The primary source of journal impact factors is the Journal Citation Reports, published annually. Unfortunately, very few physical therapy journals are included in Journal Citation Reports, so very few physical therapy journals have impact factors. This means that those journals are unable to be benchmarked against similar journals. More importantly, journals without impact factors are unlikely to be listed on Medline (PubMed), the portal through which most of the international community of clinicians and researchers learn about what research is being done. Consequently, a common aspiration of most physical therapy journals is to become listed in the Journal Citation Report. I know that Professors Tania de Fátima Salvini and Sérgio Teixeira Fonseca have been working to put in place policies that will ensure that Revista Brasileira de Fisioterapia will become listed as soon as possible, and I commend them for their excellent work in this regard. In the longer term, I hope that the society will be able to assist journals with their applications for listing in the Journal Citation Report.

WCPT played a central role in bringing together physical therapy journal editors for the first time back in 2003, and they continue to provide support. The ISPJE has committed to becoming a "network" affiliated with WCPT. This means, amongst other things, that the ISPJE web site will be hosted and maintained by WCPT. Readers who are interested in the work of the ISPJE will soon be able to visit the ISPJE web site on the WCPT web site at www.wcpt.org.

Dr Rob Herbert

University of Sydney Secretary, International Society of Physiotherapy Journal Editors

\section{References $: \because$.}

1. Katikireddi SV. HINARI: bridging the global information divide. BMJ. 2004;328:1190-3.

2. World Medical Association Ethics Unit Declaration of Helsinki. Acesso em 2007 Dez 10. Disponível em: http://www.wma.net/e/ethicsunit/helsinki.htm.

3. Seglen P0. Why the impact factor of journals should not be used for evaluating research. BMJ. 1997;314:498-502.

4. Garfield E. Citation indexes for science. A new dimension in documentation through association of ideas. Science. 1955;122 (new series):108-11. 